\title{
Urbanization and species-energy relationships
}

\author{
Lucas M. Leveau
}

Departamento de Ecología, Genética y Evolución, Facultad de Ciencias Exactas y Naturales, Universidad de Buenos Aires - IEGEBA (CONICET - UBA), Ciudad Universitaria, Pab 2, Piso 4, Buenos Aires 1426, Argentina. Email:

lucasleveau@yahoo.com

\begin{abstract}
Species-energy relationships (SER) have been used scarcely to predict responses of biodiversity to changes in land use. In this work, two hypothesis of the SER were tested on bird communities along urbanization gradients: the increasing population size (IPS) and the niche position (NP) hypotheses. The IPS hypothesis states that sites with more primary productivity have more individuals, decreasing the probability of extinction and increasing species richness. The HPN predicts that sites with greater primary productivity and environmental heterogeneity allow the availability of a greater variety of resources and the presence of specialist species, thus increasing species richness. The hypothesis of habitat heterogeneity was evaluated by which more complex habitats provide more variety of resources and greater species richness. Birds were counted along three urban-rural gradients in the Pampean region of Argentina during the breeding season. The productive energy was measured from the NDVI and the environmental heterogeneity through the Shannon-Wiener diversity index, calculated with the percentage coverage of different substrates. Bird richness and habitat diversity were higher at intermediate levels of urbanization, while primary productivity had a negative relationship with urbanization. Although there was a positive relationship between bird richness and abundance, there was no positive relationship between bird abundance and primary productivity. Bird richness showed a positive relationship with habitat diversity and primary productivity; although path analysis revealed that the habitat diversity increased bird richness through an increase of bird abundance. The NP hypothesis was the most consistent to predict the bird richness along urban-rural gradients.
\end{abstract}

Key-words: abundance, birds, composition, richness, habitat complexity, path analysis, urban 


\section{Introduction}

Species-energy relationships have been increasingly invoked over the last three decades to explain the spatial and temporal variation of species richness (Wright 1983, Rosenzweig 1995, Evans et al. 2005). Depending on the spatial scale and taxa, species richness may increase monotonically with energy, or may initially increase but then decline at higher energy levels in a unimodal relationship (Mittelbach et al. 2001, Pärtel et al. 2007, Fraser et al. 2015). Despite a large number of studies published about the species-energy relationship, there is a need to understand the mechanism underlain such relationship. Evans et al. (2005) identified nine general mechanisms that may generate positive species-energy relationships at the macroscale. However, several mechanisms such as the increasing population size (IPS) and the niche position (NP) hypothesis may be tested at smaller scales.

Although the species-energy relationships have been extensively studied in natural environments (Tellería et al. 1992, Srivastava and Lawton 1998, Honkanen et al. 2010), there are few studies in heavily impacted environments. One of the most extreme human alterations on Earth is the urbanization of natural and rural areas. Through habitat loss and fragmentation, pollution and altered resource flow, urbanization promotes a biodiversity loss (Grimm et al. 2008, Shanahan et al. 2014). On the other hand, urbanization is thought to increase animal abundance through the increase of subsidized food by humans and a decrease of predation (Shochat et al. 2006, but see Saari et al. 2016). Therefore, lower species richness and a higher abundance in urban environments disagree with the IPS mechanism, which states that higher population sizes promote higher species richness by reducing extinction risk (Srivastava and Lawton 1998, 
Forsman and Mönkkönen 2003, Evans et al. 2005). However, Chiari et al. (2010) tested this mechanism along the urban gradient of Florence (Italy) finding a positive speciesabundance relationship.

Habitat heterogeneity and energy are potential indicators of the niche position hypothesis (Evans et al. 2005, Hurlbert 2004). More energy availability and higher habitat heterogeneity are indicators of more resource types that are above the abundance threshold at which they can support a viable population (see Figure 2 in Evans et al. 2005). Therefore, there can be a higher number of niche position specialists in sites with high habitat complexity and high energy availability, elevating the species richness compared to sites with low habitat heterogeneity and energy availability (Hurlbert 2004, Honkanen et al. 2010, Elo et al. 2012). Moreover, as the number and quantity of resources increases, they are divided more equitably among a greater variety of foraging habitats; then, a lower dominance is expected as energy availability and habitat diversity increase (Hurlbert 2004). Due to this increase of new resource types changes along the gradient, a shift of species composition is expected because generalist species are replaced by specialist species (Harrower et al. 2017).

The habitat heterogeneity hypothesis $(\mathrm{HH})$ is another fundamental mechanism explaining the spatial variation of bird richness (MacArthur 1964, Hurlbert and Haskell 2003, Tews et al. 2004). A more variety of vegetation types is related to a greater quantity of different ways to obtain resources, resulting in a higher coexistence of species (Rosenzweig 1995). But the importance of habitat heterogeneity determining the species richness in urban environments has been scarcely studied. Intermediate levels of urbanization characterized by detached houses with yards are generally composed by different layers of vegetation favouring higher habitat diversity than rural or natural areas, especially for arid shrubland and grassland biomes (McKinney 2002, Miller et al. 
2001, Leveau 2013a). This, in turn, may favour higher animal species richness in suburban areas, forming a unimodal species richness-urbanization relationship (Blair 1996, Leveau and Leveau 2005, Tratalos et al. 2007).

The aim of this study is to evaluate which mechanism is more likely explaining the bird species richness variation along three urban-rural gradients of the Pampean region, Argentina. Although several studies have proposed theoretical models of bird richness response to urbanization (Lepczyk et al. 2008, Filloy et al. 2018), species-energy relationships have been scarcely studied and, to my knowledge, several hypotheses have never been explored simultaneously in urban environments yet. Unlike natural systems, in which primary productivity and habitat diversity are usually correlated (Hurlbert 2004), urban-rural gradients in central Argentina allows to separate the effects of these variables because agricultural areas can have a high primary productivity but a low habitat heterogeneity due to crops dominance (Leveau 2013a, Leveau et al. 2018). Due to bird richness has been shown an unimodal relationship with urbanization in the study area (Leveau and Leveau 2004, 2005), increasing at intermediate levels of urbanization that have both high primary productivity and habitat diversity (Leveau 2013a, Leveau et al. 2018), I expect that the NP hypothesis will explain more clearly the spatial variation of bird richness in central Argentina. On the other hand, Path analyses is a powerful statistical approach in testing and developing the structural hypothesis with both indirect and direct causal effects (Fan et al. 2016), which has been used in studies of speciesenergy relations (Jonsson et al. 2011, Elo et al. 2012, McCain et al. 2018). Therefore, a Path analysis was performed to analyze the direct and indirect effects of primary productivity, habitat diversity and bird abundance on bird richness. 


\section{Methods}

\subsection{Study area}

The study was made in three cities of the Pampean region, in Buenos Aires province (Argentina): Mar del Plata (615 350 inhabitants), Balcarce (38 823 inhabitants) and Miramar (29 629 inhabitants). The city sizes in this study controls for the city-size effect found in other studies, focusing on cities of more than 20000 inhabitants (Jokimäki and Kaisanlahti-Jokimäki 2003, Garaffa et al. 2009). The maximum distance between the cities in Argentina was $59 \mathrm{~km}$ (between Balcarce and Miramar), thus the effects of latitude or climate are minimum. These cities are surrounded by a landscape composed of cultivated land, pastureland, grasslands and exotic tree plantations. The climate is temperate and the maximum mean temperature is $20.3^{\circ} \mathrm{C}$ during January and the mean annual precipitation is $923.6 \mathrm{~mm}$ (data from the Meteorological National Service).

\subsection{Bird census}

Bird surveys were made in three habitat types: 1) urban centre; 2) suburban areas composed of detached houses with yards; and 3) rural areas, composed by crops and pastures (Figure 1). In each habitat I placed five transects of 100 x $50 \mathrm{~m}$ separated each other by at least $200 \mathrm{~m}$. During each breeding season, corresponding to spring-summer of the years 2011-2012 and 2012-2013, transects were visited twice totalling four visits to each transect. Surveys were conducted in the first $4 \mathrm{~h}$ after dawn on days without rain or strong winds, and all birds seen or heard were counted, except those flying over the top of buildings or trees or below that height but without feeding activity. 


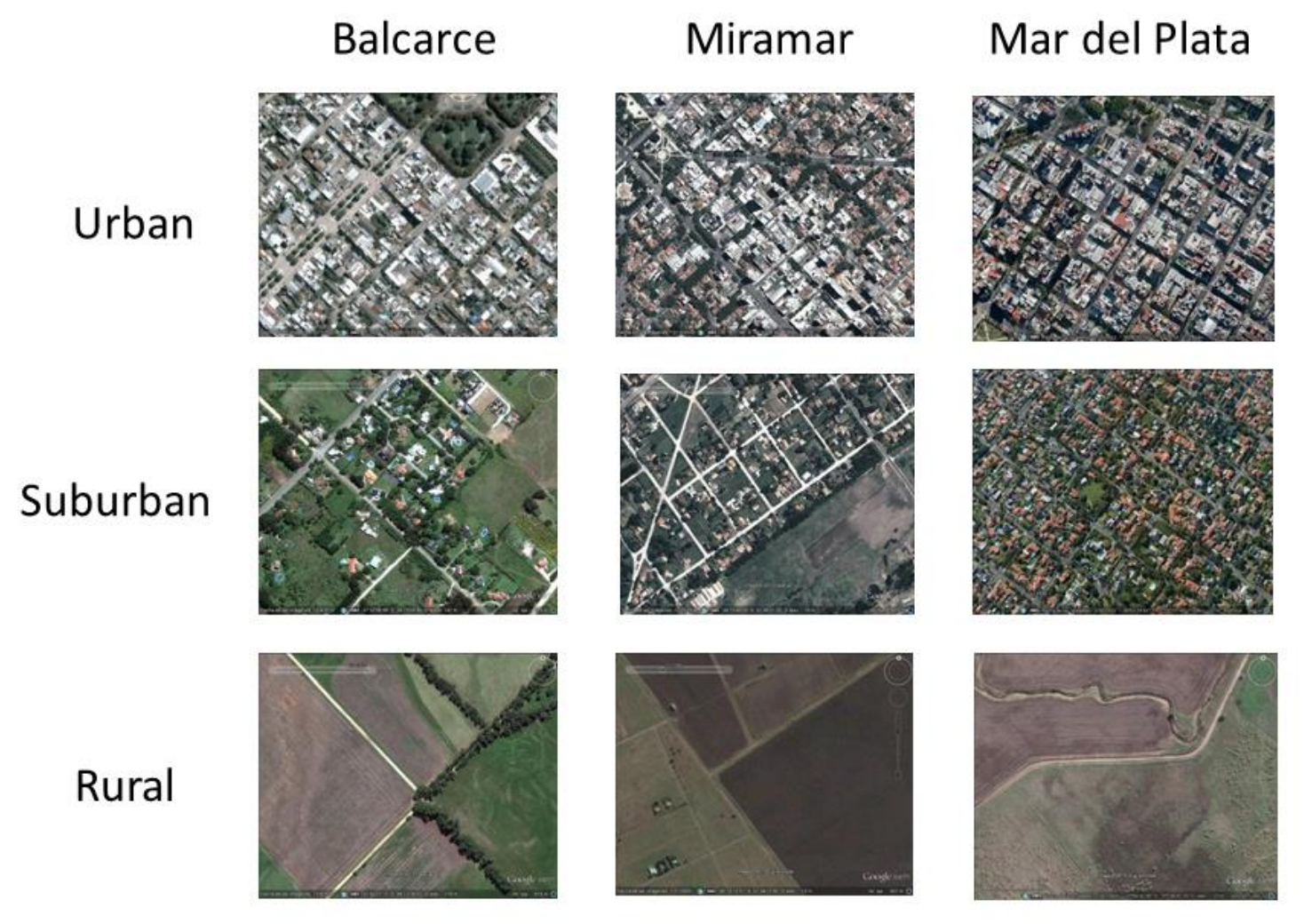

Figure 1. Study design showing Google earth images of surveyed habitat types (rows) along urban-rural gradients of three cities (columns) in central Argentina.

\subsection{Urbanization, habitat diversity and primary productivity}

In each transect, two circles of $25 \mathrm{~m}$ radius were located, one in the centre of the first 50 $\mathrm{m}$ along transects and the other in the centre of the remaining $50 \mathrm{~m}$. In each circle, the following variables were estimated visually: 1) percentage coverage of trees, 2) shrubs, 3) lawn (managed herbaceous vegetation), 4) buildings, 5) non-managed herbaceous vegetation, 6) cultivated land, and 7) paved roads. We summed the percentage cover of buildings and paved roads to get a measure of impervious surface cover in each circle and averaged values of both circles in each transect. On the other hand, habitat diversity in each transect was estimated using the Shannon index, which incorporated the percent cover of trees, shrubs, lawn, herbaceous vegetation, cultivated land and buildings. When 
the percentage cover of habitat components exceeded $100 \%$, values were corrected for up to $100 \%$.

For primary productivity I used the Normalized Difference Vegetation Index (NDVI), which is a measure of greenness that correlates positively with the net primary productivity (Rouse et al. 1974; Pettorelli et al. 2005) and is assumed to correlate positively with production of the food available to birds (Hurlbert and Haskell 2003). The product MOD13Q1 from the MODerate resolution Imaging Spectroradiometer (MODIS sensor; Terra satellite) was used (Justice et al. 2002), available in https://lpdaac.usgs.gov/products/modis_products_table, which provides NDVI values in periods of 16 days with a spatial resolution of $250 \mathrm{~m}$ (Huete et al. 2002). For each period, an algorithm applies a filter to the data based on quality, cloud and viewing geometry. Then, the best observation of each pixel is selected, which represented the NDVI value of that period. The MODIS products are distributed according to tiles, which have $1200 \times 1200 \mathrm{~km}$ in a sinusoidal projection. In this study, the h13v12 tile images were downloaded. Images encompassing the first and second visit of each breeding season were downloaded, and NDVI values were averaged for each transect. Images were referenced using the MODIS reprojection Tool software, (https://lpdaac.usgs.gov/tools/modis_reprojection_tool), using the UTM projection. Then, the images were reprojected again to the Argentina Gauss-Krüger projection. Although the transect sizes (0.5 ha) were much smaller than the pixel sizes (6.25 ha), it was assumed that the NDVI values obtained for each transect represent the resources available for birds. On the other hand, birds may use resources in areas larger than the transect size. Hostetler and Holling (2000) found that birds in urban environments may have sufficient resources at areas of $0.2 \mathrm{~km}^{2}$ to $1.5 \mathrm{~km}^{2}$. Bino et al. (2008) found that bird richness had the best fit to NDVI when it was calculated at a pixel size of 14.8 ha, 
higher than their sampling unit size (point counts of $50 \mathrm{~m}$ radius), suggesting that the sensor MODIS may be efficient in depicting resources available for birds.

\subsection{Statistical analysis}

First, I wanted to explore the relationship between impervious cover (paved roads and buildings) and the primary productivity and habitat diversity. Due to the possible presence of non-linear relationships among variables, Generalized Additive Models (GAMs) with a Gaussian distribution of errors were conducted using the mgcv package of R (Wood 2011, R Development Core Team 2011).

Bird richness in each transect was calculated using a capture-recapture approach which assumes heterogeneity in detection probability among species and sites (Burnham and Overton 1979; Boulinier et al. 1998). This procedure uses a jackknife estimator associated with model M(h) (Burnham and Overton 1978, 1979; Otis et al. 1978), which estimates bird species richness and species detection probability. Therefore, we took into account possible differences in detectability among species within a transect and possible differences in detectability among transects. These estimates were computed using COMDYN software (Hines et al. 1999), with presense-absence data of species in the four visits to each transect. On the other hand, bird abundance was estimated as the mean number of birds recorded during the four visits to each transect. Bird dominance was calculated as the proportion of bird abundance of the two most abundant species over the total of bird species abundances during each of the four visits to the sampling units; an average of bird dominance over the four visits was calculated.

I tested three mechanisms that would explain the bird richness variation along the three urban-rural gradients. First, I evaluated the IPS hypothesis, where I expected a direct 
relationship between bird richness and abundance and a direct relationship between bird abundance and primary productivity. Second, the NP hypothesis was evaluated, where an increase in bird richness and a decrease in bird dominance was expected in sites with high primary productivity and habitat diversity. Moreover, a significant change in species composition was expected along the gradient of primary productivity and habitat diversity. Finally, I tested the $\mathrm{HH}$ hypothesis, where a direct relationship between bird richness and habitat diversity was expected. Because NP and HH models were nested, a Likelihood ratio test (LRT) was performed among them to test the significance of primary productivity explaining the variation of bird richness along the gradients.

Due to the nested design of the study, in which transects were nested in cities, Generalized Linear Mixed Models (GLMMs) were conducted to test the different mechanism explaining bird richness along the urban gradients. Bird richness data were $\log$ transformed to improve normality and homoscedasticity of residuals. The city was deemed as a random factor, and the package nmle in $\mathrm{R}$ was used. The significance of the nested models was assessed by comparing them with Generalized least squares (GLSs) models through an LRT. In all cases, the random effect was not significant (P > 0.05); therefore, I conducted GLSs. The correlation between primary productivity and habitat diversity was low (Pearson coefficient, $r=0.31$ ).

Bird species composition was analyzed by a Non-metric multidimensional scaling (NMDS). A matrix of bird species as columns and bird abundance in each sampling unit as rows was used to calculate a Bray-Curtis dissimilarity matrix. Then, an NDMS was performed and the values of primary productivity and habitat diversity were correlated to the resultant ordination by the function envfit of the package vegan in $\mathrm{R}$ (Oksanen et al. 2007). The arrow shows the direction of the environmental gradient, and the length 
of the arrow is proportional to the correlation between the environmental variable and the ordering of the NMDS (Oksanen 2015). Only significant vectors $(\mathrm{P}<0.05)$ were plotted.

I explored direct and indirect effects of bird abundance, primary productivity and habitat diversity on bird richness through Path analysis (Grace and Pugesek 1998). The following relationships were tested: 1) bird richness was directly related to bird abundance, primary productivity and habitat diversity; 2) bird abundance was related to primary productivity and habitat diversity; and 3) primary productivity was related to habitat diversity. Models were adjusted by a backward selection with the anova function (see Appendix S1 in Grace et al. 2014), using the lavaan package in R (Rosseel 2012). The final model was selected through Chi-square tests $\left(\chi^{2}\right)$, which try out the hypothesis that there is a discrepancy between the model-implied covariance matrix and the original covariance matrix (Fan et al. 2016). Then, the non-significant discrepancy is preferred $(\mathrm{p}>0.05)$. The root mean square error of approximation (RMSEA) and standardized root mean square residual (SRMR) are "badness of fit" indices where 0 indicates the perfect fit and higher values indicate the lack of fit (Fan et al. 2016). The lavaan package performs a test which hypothesis is that RMSEA is less than or equal to 0.05, a cutoff sometimes used for "close" fit. A p-value greater than 0.05 does not reject the hypothesis and, therefore, the model has a good fit. The SRMR index should be less than 0.09 to be acceptable (Fan et al. 2016). Finally, the Comparative fit index (CFI) ranges between 0.0 and 1.0, and represents the amount of variance that has been accounted for in a covariance matrix; a value close to 0.95 or higher is acceptable (Fan et al. 2016). Bird abundance data was divided by 10 to have similar variance values to primary productivity and habitat diversity. 


\section{Results}

A total of 54 species and 2200 individuals were counted (Table 1). Most abundant species were the House sparrow (Passer domesticus, $27 \%$ of individuals), the Eared Dove (Zenaida auriculata, $14 \%$ ) and the Rock Dove (Columba livia, $12 \%$ ). The three habitat types have different bird composition. Urban centres were dominated by the Rock Dove, the Eared Dove and the House Sparrow, whereas suburban areas have more species and were dominated by the House Sparrow, the Eared Dove and the Picazuro Pigeon (Patagioenas picazuro). The rural areas were dominated by the Rufous-collared Sparrow (Zonotrichia capensis), the Grassland Yellow-finch (Sicalis luteola) and the House Sparrow.

Table 1. List of species observed in urban, suburban, and rural habitats of three cities in central Argentina.

Habitat

Common name

Red-winged Tinamou

White-faced Ibis

White-tailed Kite

Southern Lapwing

Rock Dove

Picazuro Pigeon
Scientific name

Rhynchotus rufescens

rhru

plch

elle

vach

coli

Columba livia

Patagioenas picazuro
Species code

Urban Suburban Rural 
Spot-winged Pigeon

Earde Dove

Picui Dove

Guira Cuckoo

Burrowing Owl

Short-eared Owl

Glittering-bellied

Emerald

White-throated

Hummingbird

Green-barred

Woodpecker

Campo Flicker

Chimango Caracara

American Kestrel

Monk Parakeet

Rufous Hornero

Firewood-gatherer

Small-billed Elaenia
Patagioenas maculosa

pama

15

15

5

Zenaida auriculata

zeau

140

130

29

Columbina picui

copi

0

5

0

Guira guira

gugu

0

2

4

Athene cunicularia

atcu

0

0

6

Asio flammeus

asfl

0

0

3

Chlorostilbon lucidus

chlu

4

9

2

Leuchloris albicollis leal

0

8

0

Colaptes

come

0

5

1

melanochloros

Colaptes campestris

coca

0

0

4

Milvago chimango mich

5

6

8

Falco sparverius

fasp

0

0

7

Myiopsitta monachus

mymo

0

2

33

Furnarius rufus

furu

3

80

14

Anumbius anumbi

anan

0

0

5

Elaenia parvirostris

elpa

0

25

0 
White-crested

Serpophaga subcristata

sesu

Hymenops

hype

0

0

1

perspicillatus

Cattle Tyrant

Great Kiskadee

Tropical Kingbird

Tyrannus

tyme

tysa

prta

prch

3

0

3

Southern Martin

White-rumped Swallow

Thacycineta leucorrhoa tale

prmo

1

0

0

Barn Swallow

Hirundo rustica

hiru

Troglodytes aedon

trae

3

21

11

Rufous-bellied Thrush

Turdus rufiventris

turu

6

40

0

Chalk-browed

Mimus saturninus

misa

2

35

18

Mockingbird

Correndera Pipit
Anthus correndera

anco

0

0 
Blue-and-yellow

Pipraeidea bonariensis pibo

0

5

0

Tanager

Saffron Finch

Sicalis flaveola

sifl

0

13

2

Grassland Yellow-finch

Sicalis luteola

silu

0

0

55

Great Pampa-finch

Embernagra platensis

empl

0

0

4

Double-collared

Sporophila

spca

0

2

16

Seedeater

caerulescens

Rufous-collared Sparrow

Zonotrichia capensis

zoca

5

29

100

Tropical Parula

Setophaga pititayumi

sepi

0

0

Yellow-winged

Agelasticus thilius

agth

0

2

Blackbird

Brown-and-yellow

Pseudoleistes virescens

psvi

0

0

1

Marshbird

Bay-winged Cowbird

Agelaioides badius

agba

0

9

11

Screaming Cowbird

Molothrus rufoaxillaris

moru

0

2

0

Shiny Cowbird

Molothrus bonariensi

mobo

2

29

16

Long-tailed

Leistes loyca

lelo

0

0

3

Meadowlark

White-browed

Leistes superciliaris

lesu

0

0

Blackbird 
European Greenfinch

Hooded Siskin

House Sparrow
Chloris chloris

Spinus magellanica

Passer domesticus chch

spma

pado
7

10

3

1

.

274

275

Primary productivity declined with impervious surface cover $\left(\mathrm{r}^{2}=0.88, \mathrm{~F}=50.53\right.$, estimated degrees of freedom [edf] $=5.48, \mathrm{P}<0.001, \mathrm{n}=45$; Figure 2), whereas habitat diversity was highest at intermediate levels of impervious surface $\left(\mathrm{r}^{2}=0.53, \mathrm{~F}=14.40\right.$, edf $=2.73, \mathrm{P}<0.001, \mathrm{n}=45)$. Therefore, energy availability was higher in rural areas whereas habitat complexity increased in suburban areas. Bird richness increased at intermediate levels of urbanization $\left(\mathrm{r}^{2}=0.44, \mathrm{~F}=12.55\right.$, edf $\left.=2.32, \mathrm{P}<0.001, \mathrm{n}=45\right)$. 

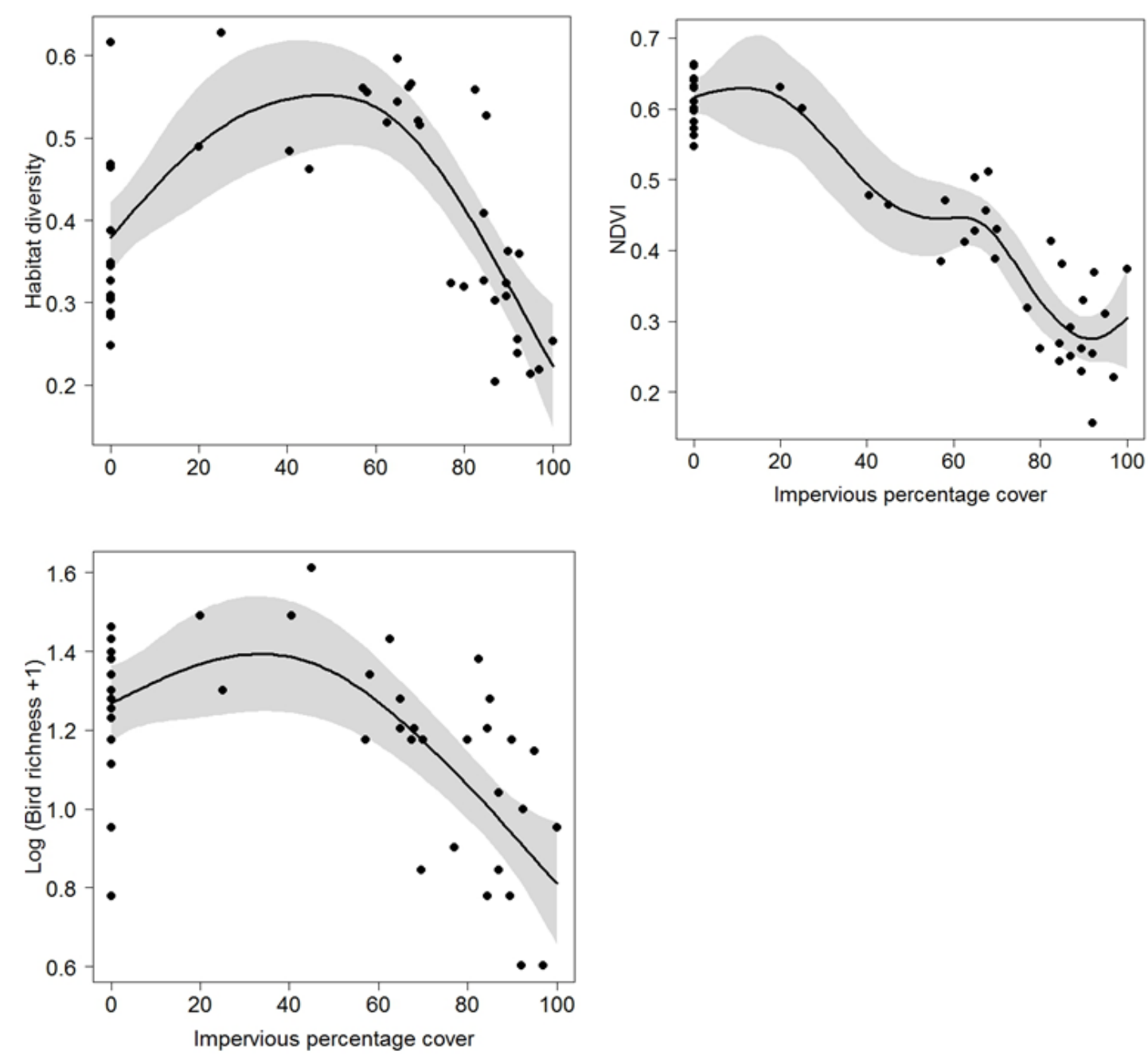

Figure 2. Relationships between habitat diversity (H’index), primary productivity (NDVI), bird richness (log) and impervious percentage cover in three cities of central Argentina. Models were constructed based on Generalized additive models.

Although bird species richness was related positively with bird abundance (Table 2), the latter was not related significantly with primary productivity (Figure 3). Therefore, the IPS hypothesis is not supported by results. On the other hand, although bird species richness had a positive relationship with habitat diversity supporting the $\mathrm{HH}$ mechanism (Table 2), the inclusion of primary productivity to the model had a better fit of data (LRT, $\mathrm{F}=18.22, \mathrm{P}<0.001)$ (Figure 4). Moreover, dominance declined with higher primary productivity and habitat diversity (Figure 4), whereas species composition 
varied according to changes in habitat diversity and primary productivity along the gradients (Figure 5). Then, the NP mechanism would be the most likely explaining the variation of bird species richness along the urban gradients studied.

Table 2. Main hypothesis and statistical models explaining the spatial variation of bird richness, abundance and dominance along urban-rural gradients of three cities of central Argentina.

\begin{tabular}{|c|c|c|c|c|c|c|}
\hline Hypothesis & $\begin{array}{l}\text { Dependent } \\
\text { variable }\end{array}$ & $\begin{array}{l}\text { Independent } \\
\text { variable }\end{array}$ & $\begin{array}{l}\text { Parameter } \\
\text { value }\end{array}$ & $\mathrm{t}$ test & $\mathrm{P}$ & AIC \\
\hline \multirow{5}{*}{$\begin{array}{l}\text { Increasing } \\
\text { population size }\end{array}$} & Log (Bird & Intercept & 0.94 & 11.53 & 0.000 & 3.26 \\
\hline & richness) & & & & & \\
\hline & & $\begin{array}{l}\text { Bird } \\
\text { abundance }\end{array}$ & 0.02 & 2.93 & 0.006 & \\
\hline & Bird abundance & Intercept & 12.18 & 4.32 & 0.000 & 292.38 \\
\hline & & NDVI & -0.63 & -0.11 & 0.920 & \\
\hline \multirow[t]{5}{*}{ Niche position } & $\begin{array}{l}\text { Log (Bird } \\
\text { richness) }\end{array}$ & Intercept & 0.45 & 4.12 & 0.000 & -21.65 \\
\hline & & H habitat & 0.78 & 3.62 & 0.000 & \\
\hline & & NDVI & 0.86 & 4.83 & 0.000 & \\
\hline & Dominance & Intercept & 1.18 & 18.37 & 0.000 & -68.28 \\
\hline & & $\mathrm{H}$ habitat & -0.82 & -6.03 & 0.000 & \\
\hline
\end{tabular}




$\begin{array}{lllllll} & & \text { NDVI } & -0.35 & -3.14 & 0.003 & \\ & & & & & & \\ \text { Habitat } & \text { Log (Bird } & \text { Intercept } & 0.69 & 6.18 & 0.000 & -4.63 \\ \text { diversity } & \text { richness) } & & & & & \end{array}$

H habitat $\quad 1.14 \quad 4.3 \quad 0.000$
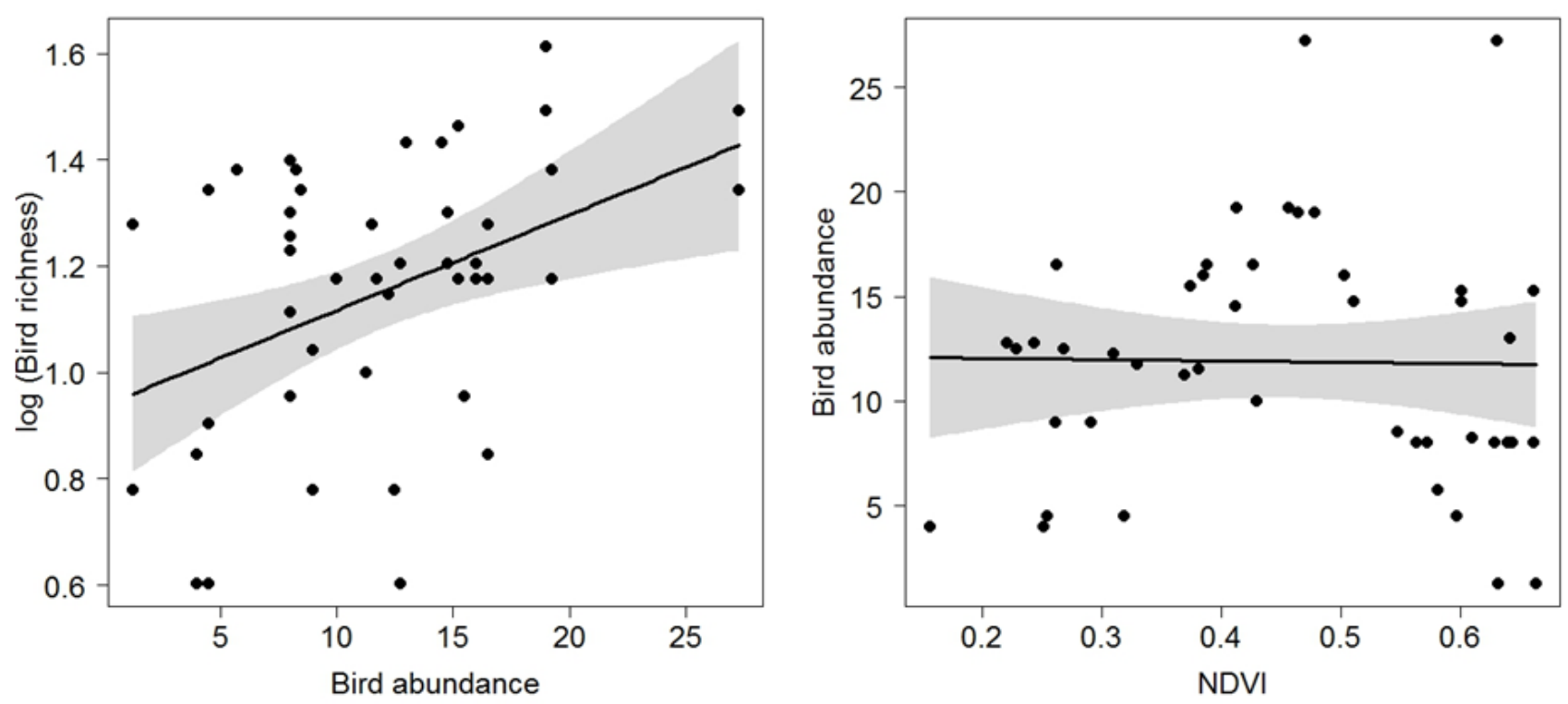

Figure 3. Relationships between bird richness and bird abundance and between bird abundance and primary productivity (NDVI) along urban-rural gradients of three cities in central Argentina. 

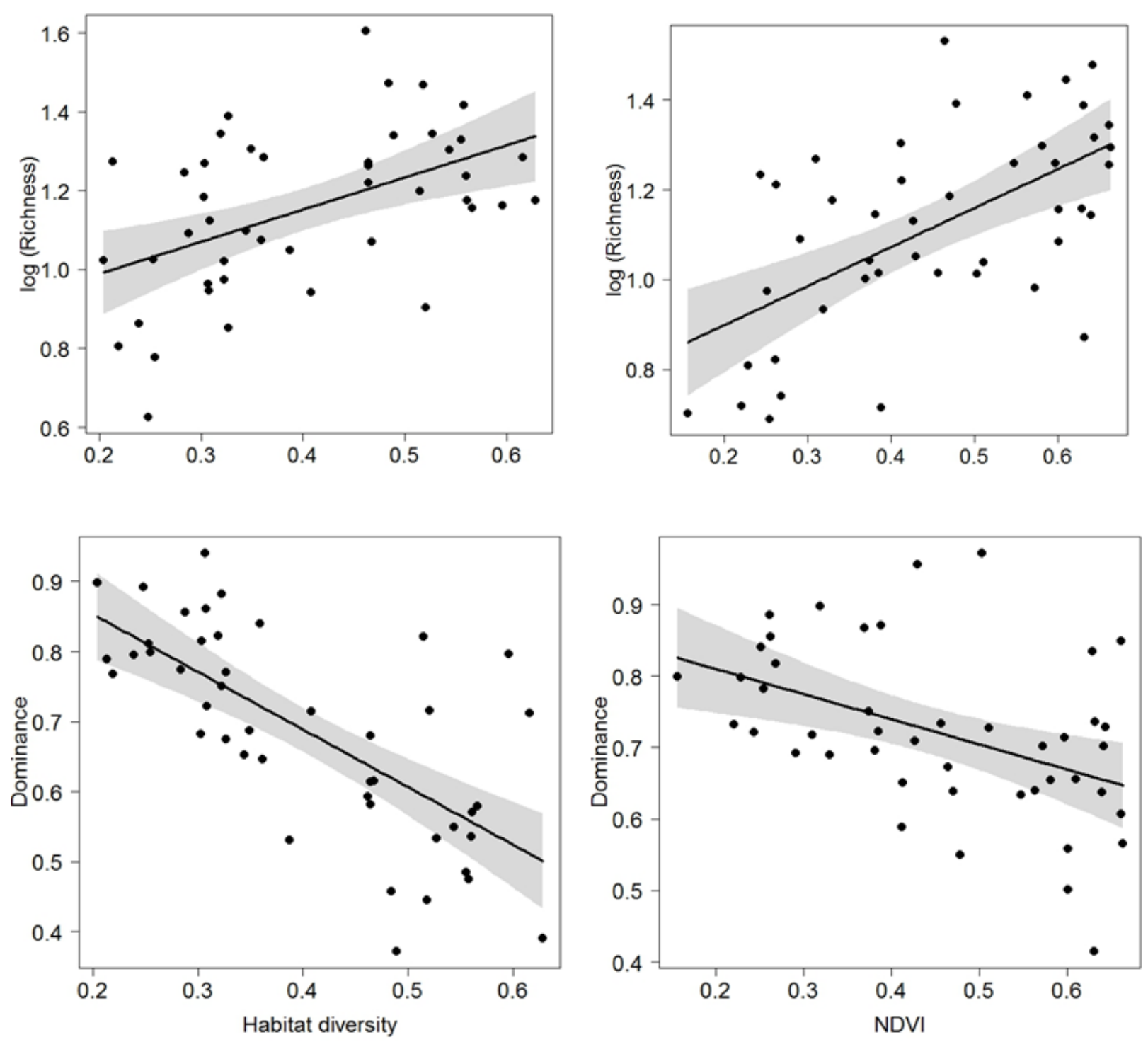

Figure 4. Relationships between bird richness, habitat diversity and primary productivity (NDVI), and relationships between bird dominance and habitat diversity and primary productivity along urban-rural gradients of three cities in central Argentina. 


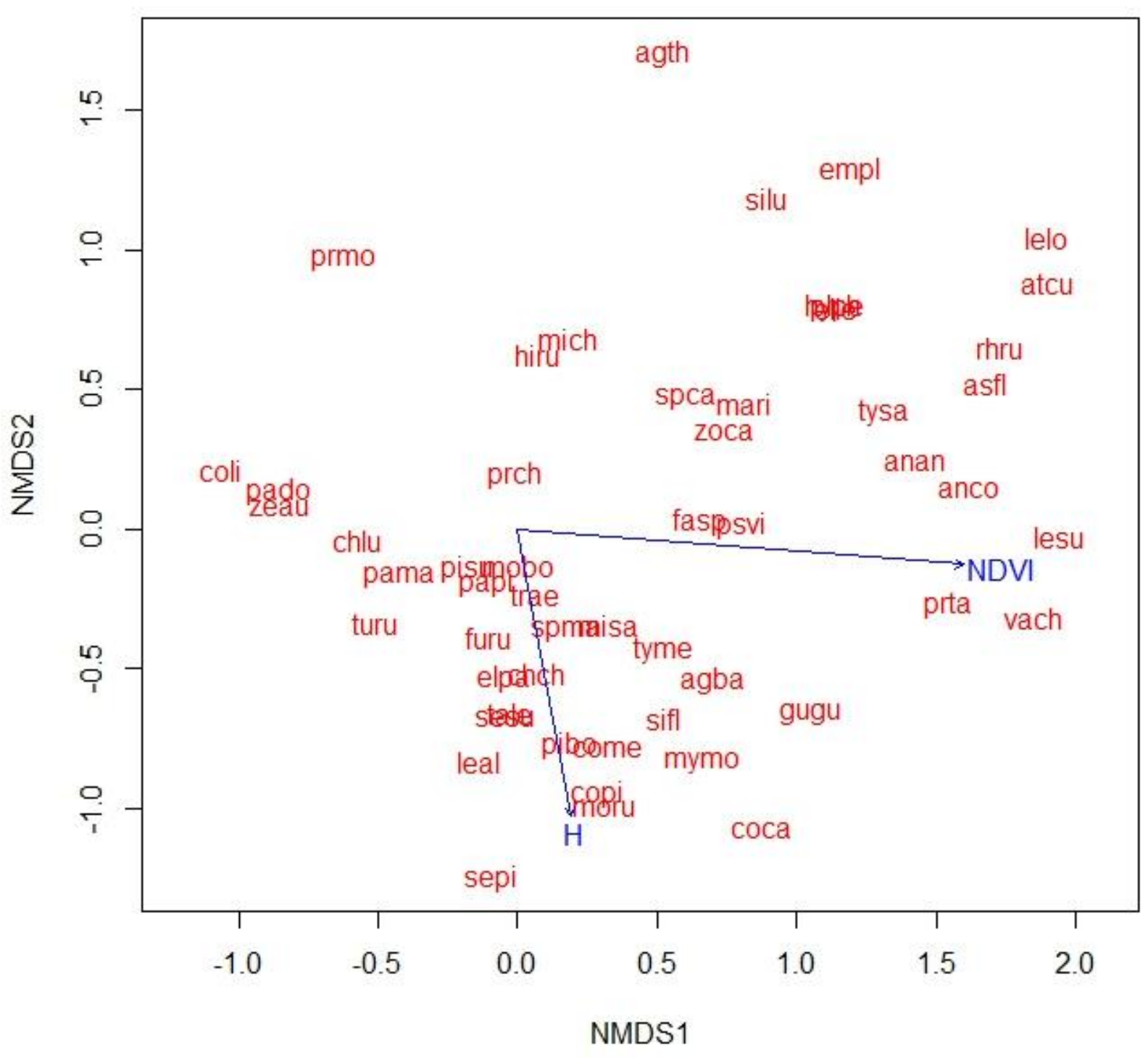

Figure 5. Non-metric multidimensional scaling showing the relationship between species composition along two axes and primary productivity (NDVI) and habitat diversity $(\mathrm{H})$ along three urban-rural gradients in central Argentina. Stress $=0.18$. For species names see codes in Table 1 . 
Path analysis had a good fit $(\chi 2$ test, $\mathrm{p}=0.074$; RMSEA $=0.19, \mathrm{p}=0.096$; SRMR $=$ 0.09 ; and $\mathrm{CFI}=0.95)$. The model selected revealed direct relationships of primary productivity and bird abundance with species richness (Figure 6). Habitat diversity had a direct relationship with bird abundance and primary productivity, having an indirect effect on bird richness.

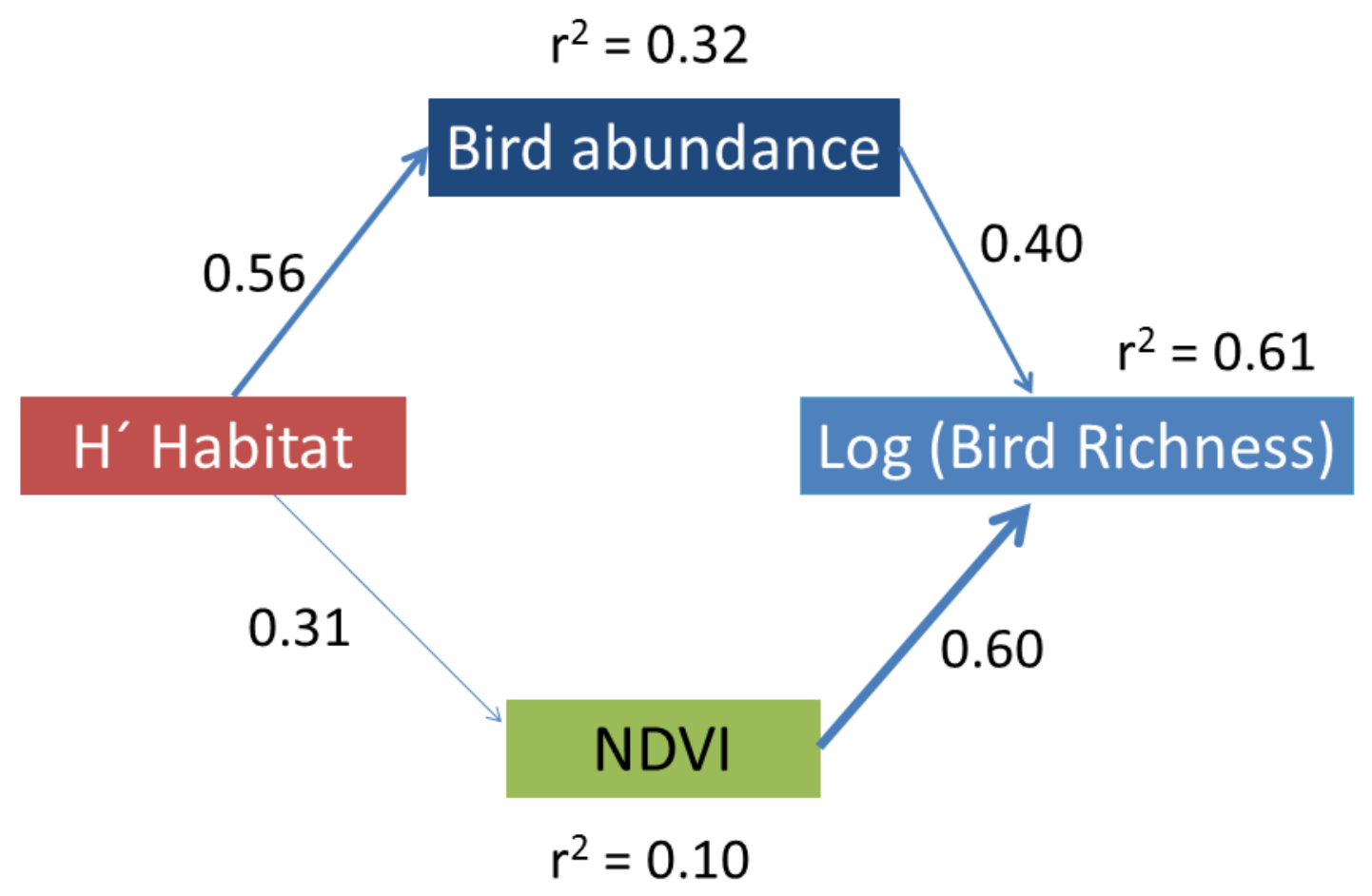

Figure 6. Path analysis showing the direct and indirect relationships between habitat diversity, primary productivity, bird abundance and bird richness. Standardized coefficients are showed $(\mathrm{P}<0.05)$ with $\mathrm{r}$-squared coefficients.

\section{Discussion}

Along the three urban-rural gradients analyzed in the Pampean region, urbanization affected negatively the primary productivity but increased the habitat heterogeneity at intermediate values of impervious surfaces. On the other hand, bird species richness 
was higher at sites with the highest primary productivity and habitat diversity.

Therefore, this result supports the NP hypothesis, which states that a more quantity and variety or resources allow the permanence of a higher number of species (Abrams 1995, Hurlbert 2004, Honkanen et al. 2010, Elo et al. 2012).

The suburban areas are the typical part of the urban-rural gradient where primary productivity and habitat diversity meets. Humans create yards with several vegetation strata: lawn, shrubs and trees. Usually, it is used a variety of shrub and tree species that provide a diversity of floral and fruit resources. The primary productivity is enhanced by the use of fertilizers and irrigation (Lepczyk et al. 2004). Buildings and trees may provide nesting places, allowing a higher species richness than highly urbanized areas and rural areas. As a result, suburban areas not only were inhabited by species that have a generalist diet and nest in buildings, such as the Rock Dove and the House Sparrow, but also by species that nest in trees and have an insectivorous diet, such as the Rufous Hornero (Furnarius rufus) and the Chalk-browed Mockingbird (Mimus saturninus), or a nectarivorous diet, as in the case of the White-throated Hummingbird (Leucochloris albicollis) and the Glittering-bellied Emerald (Chlorostilbon lucidus).

Highly urbanized areas had both lower habitat diversity and lower primary productivity, as a result of a dominance of impervious cover. However, they are inhabited by a few species (the Rock Dove, the Eared Dove and the House Sparrow) that have high abundances (see Table 2). These species may exploit food resources not resultant of primary productivity but instead provided by humans, such as food discards.

Rural areas had the highest primary productivity but lower habitat diversity than suburban areas, as a result of the dominance of crops. Therefore, sites were occupied mainly by granivorous species that nest on the ground, such as the Rufous-collared 
Sparrow and the Grassland Yellow-finch. However, an increase of habitat heterogeneity by the planting of trees or the presence of houses may increase species richness by allowing the presence of species that nest in trees, such as the the Moonk Parakeet (Myiopsitta monachus) and the Fork-tailed Flycatcher (Tyrannus savanna), or species that nest in holes, such as the House Sparrow or the Grey-breasted Martin (Progne chalybea).

Although the MIH has been postulated as a mechanism explaining bird richness variation along urbanization gradients (Chiari et al. 2009), our results showed a lack of relationship between primary productivity and bird abundance. Storch et al. (2018), based on a review, have also found a lack of support to the IPS for the most of their studies analyzed. Urban areas are characterized by a number of conditions that decouple the positive relation between bird abundance and bird richness. For example, the presence of constant food waste provided by humans, nest site availability and lower predation pressure enable to a reduced number of species to thrive in highly urbanized areas (Shochat et al. 2006, Shanahan et al. 2014).

Path analysis revealed that the effect of habitat diversity on bird richness was not direct, but rather mainly through increasing bird abundance. The positive effect of habitat diversity on bird abundance has been shown to be mainly direct on bird richness (Elo et al. 2012). Our results highlight the importance to analyze what is the role of habitat diversity in the niche position hypothesis; whether its effect is direct on bird richness or indirect by increasing bird abundance. Habitat diversity may favour greater bird abundance by providing more refugees (Kohn and Leviten 1976). Alternatively, the presence of different overlapped vegetation layers may provide more volume that can hold more bird individuals per habitat area (Dean and Connell 1987). A greater number 
of individuals may increase species richness by a sampling phenomenon $\left(\mathrm{O}^{\prime} \mathrm{Connor}\right.$ 1991).

\subsection{Conservation implications}

The three processes tested have different management decisions to increase species richness along urbanization gradients (Harrower et al. 2017). If the HH hypothesis was supported, only efforts to create more diverse habitats would be adequate. If the IPS hypothesis was verified, a focus on more vegetation plantation would be good to allow higher bird richness. However, our results supported the NP hypothesis and, therefore, habitats with both high vegetation cover and a high habitat complexity would be necessary to allow a higher species richness. However, in our study area, sites with higher species richness can be inhabited by species with low conservation status that are widely distributed in the region, such as the Rufous-bellied Thrush (Turdus rufiventris), the Great Kiskadee (Pitangus sulphuratus) or the Rufous Hornero (Furnarius rufus). On the other hand, the NP hypothesis is consistent with a gradual change of species composition along the disturbance gradient (Harrower et al. 2017). Indeed, our data showed that bird communities along the urban-rural gradient were dominated by different species (Table 2). Therefore, conservation efforts also must focus on the specific habitat requirements of individual species. Although rural areas may have lower species richness than suburban areas, they are inhabited by species typical of grasslands that nest on the ground, such as the Short-eared Owl (Asio flammeus), the Grassland Yellow-finch (Sicalis luteola) and the Great Pampa-finch (Embernagra platensis).

It is evident that conservation implications are dependent on the scale of the study. If the focus is to promote bird richness within the city, more emphasis should be done to 
create areas with several types of vegetation. On the other hand, if the focus is on the consequences of urban expansion over rural areas, more importance should be put on the conservation of species typical of grasslands.

\section{Conclusions}

Although several studies have shown the importance of primary productivity (Haedo et al. 2017, Leveau et al. 2018, Filloy et al. 2018) and habitat diversity (Leveau 2013b) determining the spatial variation of species richness in urban areas, this is the first case study where both variables are considered in the context of species-energy relationships. The niche position hypothesis was supported and bird richness increased with more primary productivity and habitat diversity. However, the effect of habitat diversity was indirect through an increase of bird abundance. For a conservation point of view, this implies that focusing on quantity and variety of vegetation is the best option to enhance bird richness, but particular conservation efforts must be done to conserve grassland species which have specific habitat requirements and are negatively affected by the urban expansion.

\section{References}

Abrams, P.A. (1995) Monotonic or unimodal diversity productivity gradients: what does competition theory predict? Ecology, 76, 2019-2027.

Bino G, Levin N, Darawshi S, Van Der Hal N, Reich-Solomon A, Kark S (2008)

Accurate prediction of bird species richness patterns in an urban environment using Landsat-derived NDVI and spectral unmixing. Int J Remote Sens 29: 3675-3700. 
Blair, R. B. (1996). Land use and avian species diversity along an urban gradient. Ecological applications, 6(2), 506-519.

Boulinier T, Nichols JD, Hines JE, Sauer JR, Flather CH, Pollock KH (1998) Higher temporal variability of forest breeding bird communities in fragmented landscapes. Proc Natl Acad Sci U S A 95:7497-7501

Burnham KP, Overton WS (1978) Estimation of the size of a closed population when capture probabilities vary among animals. Biometrika 65:625-633

Burnham KP, Overton WS (1979) Robust estimation of population size when capture probabilities vary among animals. Ecology 60:927-936

Chiari, C., Dinetti, M., Licciardello, C., Licitra, G., \& Pautasso, M. (2010).

Urbanization and the more-individuals hypothesis. Journal of Animal Ecology, 79(2), 366-371.

Dean, R. L., \& Connell, J. H. (1987). Marine invertebrates in an algal succession. III. Mechanisms linking habitat complexity with diversity. Journal of Experimental Marine Biology and Ecology, 109(3), 249-273.

Elo, M., Roberge, J. M., Rajasärkkä, A., \& Mönkkönen, M. (2012). Energy density and its variation in space limit species richness of boreal forest birds. Journal of Biogeography, 39(8), 1462-1472.

Evans, K.L., Warren, P.H. \& Gaston, K.J. (2005b) Species-energy relationship at the macroecological scale: a review of the mechanisms. Biological Reviews, 80, 1-25. 
Fan, Y., Chen, J., Shirkey, G., John, R., Wu, S. R., Park, H., \& Shao, C. (2016). Applications of structural equation modeling (SEM) in ecological studies: an updated review. Ecological Processes, 5(1), 19.

Filloy, J., Zurita, G. A., \& Bellocq, M. I. (2018). Bird Diversity in Urban Ecosystems: The Role of the Biome and Land Use Along Urbanization Gradients. Ecosystems, 1-15.

Forsman, J. T., \& Mönkkönen, M. (2003). The role of climate in limiting European resident bird populations. Journal of Biogeography, 30(1), 55-70.

Fraser, L. H., Pither, J., Jentsch, A., Sternberg, M., Zobel, M., Askarizadeh, D., ... \& Boldgiv, B. (2015). Worldwide evidence of a unimodal relationship between productivity and plant species richness. Science, 349(6245), 302-305.

Garaffa, P. I., Filloy, J., \& Bellocq, M. I. (2009). Bird community responses along urban-rural gradients: does the size of the urbanized area matter?. Landscape and Urban Planning, 90(1-2), 33-41.

Grace, J. B., \& Pugesek, B. H. (1998). On the use of path analysis and related procedures for the investigation of ecological problems. The American Naturalist, 152(1), 151-159.

Grace, J. B., Adler, P. B., Stanley Harpole, W., Borer, E. T. and Seabloom, E. W. (2014), Causal networks clarify productivity-richness interrelations, bivariate plots do not. Funct Ecol, 28: 787-798

Grimm, N. B., Faeth, S. H., Golubiewski, N. E., Redman, C. L., Wu, J., Bai, X., \& Briggs, J. M. (2008). Global change and the ecology of cities. Science, 319(5864), 756760. 
Haedo, J., Gioia, A., Aráoz, E., Paolini, L., \& Malizia, A. (2017). Primary productivity in cities and their influence over subtropical bird assemblages. Urban Forestry \& Urban Greening, 26, 57-64.

Harrower, W. L., Srivastava, D. S., McCallum, C., Fraser, L. H., \& Turkington, R. (2017). Temperate grassland songbird species accumulate incrementally along a gradient of primary productivity. PloS one, 12(10), e0186809.

Hines JE, Boulinier T, Nichols JD, Sauer JR, Pollock KH (1999) COMDYN: software to study the dynamics of animal communities using a capture-recapture approach. Bird Study 46:209-217

Honkanen, M., Roberge, J. M., Rajasärkkä, A., \& Mönkkönen, M. (2010).

Disentangling the effects of area, energy and habitat heterogeneity on boreal forest bird species richness in protected areas. Global Ecology and Biogeography, 19(1), 61-71.

Hostetler M, Holling CS (2000) Detecting the scales at which birds respond to structure in urban landscapes. Urban Ecosyst 4: 25-54.

Huete AR, Didan K, Miura T, Rodriguez E (2002) Overview of radiometric and biophysical performance of the MODIS vegetation indices. Remote Sens Environ $83: 195-213$

Hurlbert, A. H. (2004). Species-energy relationships and habitat complexity in bird communities. Ecology Letters, 7(8), 714-720.

Hurlbert AH, Haskell JP (2003) The effect of energy and seasonality on avian species richness and community composition. Am Nat 161:83-97 
Jokimäki, J., \& Kaisanlahti-Jokimäki, M. L. (2003). Spatial similarity of urban bird communities: a multiscale approach. Journal of Biogeography, 30(8), 1183-1193.

Jonsson, M., Englund, G., \& Wardle, D. A. (2011). Direct and indirect effects of area, energy and habitat heterogeneity on breeding bird communities. Journal of Biogeography, 38(6), 1186-1196.

Kohn, A. J., \& Leviten, P. J. (1976). Effect of habitat complexity on population density and species richness in tropical intertidal predatory gastropod assemblages. Oecologia, 25(3), 199-210.

O'connor, N. A. (1991). The effects of habitat complexity on the macroinvertebrates colonising wood substrates in a lowland stream. Oecologia, 85(4), 504-512.

Oksanen J (2015) Vegan: an introduction to ordination. URL http://cran.r project.org/web/packages/vegan/vignettes/introvegan.pdf

Oksanen J, Kindt R, Legendre P, O’Hara B, Stevens MHH, Oksanen MJ, Suggests MAS (2007) The vegan package. Community ecology package. URL http://cran.rproject.org, http://vegan.r-forge. r-project.org/

Otis DL, Burnham KP, White GC, Anderson DR (1978) Statistical inference from capture data and closed animal populations. Wildl Monogr 62

Lepczyk, C. A., Mertig, A. G., \& Liu, J. (2004). Assessing landowner activities related to birds across rural-to-urban landscapes. Environmental Management, 33(1), 110-125.

Lepczyk, C. A., Flather, C. H., Radeloff, V. C., Pidgeon, A. M., Hammer, R. B., \& Liu, J. (2008). Human impacts on regional avian diversity and abundance. Conservation Biology, 22(2), 405-416. 
Leveau, C. M., \& Leveau, L. M. (2005). Avian community response to urbanization in the Pampean region, Argentina. Ornitol Neotrop, 16, 503-510.

Leveau, L. M. (2013a). Bird traits in urban-rural gradients: how many functional groups are there?. Journal of Ornithology, 154(3), 655-662.

Leveau, L. M. (2013b). Relaciones aves-habitat en el sector suburbano de mar del plata, argentina. Ornitologia Neotropical, 24, 201-212.

Leveau, L. M., \& Leveau, C. M. (2004). Comunidades de aves en un gradiente urbano de la ciudad de Mar del Plata, Argentina. El hornero, 19(1), 13-21.

Leveau, L. M., Isla, F. I., \& Bellocq, M. I. (2018). Predicting the seasonal dynamics of bird communities along an urban-rural gradient using NDVI. Landscape and Urban Planning, 177, 103-113.

MacArthur, R.H. (1964). Environmental factors affecting bird species diversity. Am. Nat., 98, 387-396

McCain, C. M., King, S. R., Szewczyk, T., \& Beck, J. (2018). Small mammal species richness is directly linked to regional productivity, but decoupled from food resources, abundance, or habitat complexity. Journal of Biogeography.

McKinney, M. L. (2002). Urbanization, Biodiversity, and Conservation. Bioscience, 52(10), 883-890.

Miller, J. R., Fraterrigo, J. M., Hobbs, N. T., Theobald, D. M., \& Wiens, J. A. (2001). Urbanization, avian communities, and landscape ecology. In Avian ecology and conservation in an urbanizing world (pp. 117-137). Springer, Boston, MA. 
Mittelbach, G.G., Steiner, C.F., Scheiner, S.M., Gross, K.L., Reynolds, H.L., Waide, R.B., Willig, M.R., Dodson, S.I. \& Gough, L. (2001) What is the observed relationship between species richness and productivity? Ecology, 82, 2381-2396.

Otis, D. L., K. P. Burnham, G. C. White, and D. R. Anderson. 1978. Statistical inference from capture data on closed animal populations. Wildlife Monographs 62

Pärtel, M., Laanisto, L., \& Zobel, M. (2007). Contrasting plant productivity-diversity relationships across latitude: the role of evolutionary history. Ecology, 88(5), 10911097.

Pettorelli N, Vik JO, Mysterud A, Gaillard JM, Tucker CJ, Stenseth NC (2005) Using the satellite-derived NDVI to assess ecological responses to environmental change. Trends Ecol Evol 20: 503-510.

Srivastava, D.S. \& Lawton, J.H. (1998) Why more productive sites have more species: an experimental test of theory using tree-hole communities. The American Naturalist, $152,510-529$

Storch, D., Bohdalková, E., \& Okie, J. (2018). The more-individuals hypothesis revisited: the role of community abundance in species richness regulation and the productivity-diversity relationship. Ecology letters, 21(6), 920-937.

Tews, J., Brose, U., Grimm, V., Tielbörger, K., Wichmann, M. C., Schwager, M., \& Jeltsch, F. (2004). Animal species diversity driven by habitat heterogeneity/diversity: the importance of keystone structures. Journal of Biogeography, 31(1), 79-92. 
Tratalos, J., Fuller, R. A., Evans, K. L., Davies, R. G., Newson, S. E., Greenwood, J. J., \& Gaston, K. J. (2007). Bird densities are associated with household densities. Global Change Biology, 13(8), 1685-1695.

R Development Core Team (2011) R: a language and environment for statistical computing. R Foundation Project, GNU project, Boston, Massachussetts, USA

Rosenzweig, M.L. (1995) Species diversity in space and time. Cambridge University Press, Cambridge.

Rosseel, Y. (2012). lavaan: An R package for structural equation modeling. Journal of Statistical Software, 48(2), 1-36.

Rouse JW, Haas RH, Schell JA, Deering DW, Harlan JC (1974) Monitoring the vernal advancements and retrogradation of natural vegetation. NASA/GSFC, Final Report, Greenbelt, MD, USA, 1-137.

Saari, S., Richter, S., Higgins, M., Oberhofer, M., Jennings, A., \& Faeth, S. H. (2016). Urbanization is not associated with increased abundance or decreased richness of terrestrial animals-dissecting the literature through meta-analysis. Urban ecosystems, 19(3), 1251-1264.

Shanahan, D. F., Strohbach, M. W., Warren, P. S., \& Fuller, R. A. (2014). The challenges of urban living. Pages 3-20 in Avian Urban Ecology Behavioural and Physiological Adaptations, D Gil and H Brumm (Eds.), Oxford University Press, Oxford.

Shochat, E., Warren, P. S., Faeth, S. H., McIntyre, N. E., \& Hope, D. (2006). From patterns to emerging processes in mechanistic urban ecology. Trends in ecology \& evolution, 21(4), 186-191. 
Storch, D., Bohdalková, E., \& Okie, J. (2018). The more-individuals hypothesis revisited: the role of community abundance in species richness regulation and the productivity-diversity relationship. Ecology letters, 21(6), 920-937.

Telleria, J. L., Santos, T., Sanchez, A., \& Galarza, A. (1992). Habitat structure predicts bird diversity distribution in Iberian forests better than climate. Bird Study, 39(1), 6368.

Wood SN (2011) Fast stable restricted maximum likelihood and marginal likelihood estimation of semiparametric generalized linear models. J R Stat Soc Ser B 73:3-36

Wright, D.H. (1983) Species-energy theory: an extension of species-area theory. Oikos, 41, 496-506. 